\title{
Peningkatan pendapatan masyarakat Desa Parambambe Kabupaten Takalar melalui pemanfaatan lahan bekas galian batu bata
}

\author{
Sapto Haryoko ${ }^{1}$, Hendra Jaya ${ }^{2}$ \\ ${ }^{1,2}$ Fa kultas Teknik, Universitas Negeri Makassar
}

\begin{abstract}
The purpose of the Community Partnership Program is to jointly develop a freshwater fishing bu siness . Developing a fish breeding system with a cement pond sy stem and a carpet pond system that will be adapted to the needs and conditions of the land. Provide training, direction, and marketing management regarding the cultivation of freshwater fish. Prevent damage to the surrounding environment dueto excavation to be made in to bricks. The methods of implementing Community Partnership Program (PKM) activities a re lectures, simulations, discussions, and questions and answers through training in developing a freshwater fishery business, a fish maintenance sy stem with a cement pond system and a carpet pond system, marketing management regarding the cultivation of freshwater fish, and counseling prevent environmental damage to the surrounding la nd due to excavation to be made of bricks to the community of South Ga lesong sub-district Takalar district. The trainees gained knowledge a bout the Utilization of Former Ga lian Bricks and their Impact on theenvironment, introduction of ca tfish farming techniques (Maintenance of seedlings to Sella bility), introduction of catfish culture techniques (Marketing Management and Prospects), Manufacturing of Tarpaulin \& Cement Ponds. Ba sed on the results achieved, the im plementation of tra ining to residents (farmers) Parambambe Villa ge, Ga lesong District, Takalar District can be successful because the percentage of training indicators ca $n$ be a chieved with a high score. So that at the end of the Camat training a nd the localgovernment wishes to carry out the retraining of Takalar district.
\end{abstract}

Key words: increased income, used land, fish ponds

\section{PENDAHULUAN}

Kabupaten Takalar adalah sebuah kabupaten di provinsi Sulawesi Selatan, Indonesia. Ibu kotanya terletak di Kota Takalar yang terdiri dari delapan kecamatan yaitu Pattallassang, Polongbangkeng Selatan, Polongbangkeng Utara, Galesong, Galesong Selatan, Galesong Utara, Mappakasunggu, Manggarabombang.

Menurut jenisnya, tanah di Kabupaten ini digolongkan atas tiga yaitu Alluvial, Mediteran dan Latosol. Mediteran terdiri dari : 1) Mediteran Coklat tua dengan bahan induk serpih dan tufa tuken/alkali, terdapat di Kecamatan Mangarabombang yakni Desa Lakatong dan Desa Cikowang, 2) Mediteran coklat kemerah-merahan dengan bahan induk tufa dengan batuan fulkan alkali terdapat sebagian besar di Desa Lassang, Mattompodalle bagian Timur Kecamatan Polongbangkeng Utara dan 3) Coklat Kemerah-merahan dengan bahan induk tufa dan batuan fulkan alkali yang terdapat sebagian besar di Desa Lassang,
Mattompodalle bagian Timur Kecamatan Polongbangkeng Utara. Sedangkan Alluvial terdiri dari: 1) Alluvial Hidromorf dengan endapan liat terdapat di sebagian wilayah Kecamatan Mappakasunggu yaitu desa Sanrobone, Lagaruda dan sebagian di Desa Takalar, 2) Alluvial Coklat kekelabuan dengan bahan endapan liat dan pasir terdapat di Kelurahan Pa'bundukang, Lengkese bagian Barat, batas Desa Topejawa dengan Lakatong dan 3) Alluvial Coklat kelabu dengan bahan induk endapan liat dan pasir terdapat di Kecamatan Galesong Utara, Galesong Selatan, Polongbangkeng bagian Utara.

Pada tahun 1998 akibat krisis moneter yang berakibat juga pada pertanian karena harga pupuk meningkat, maka beberapa petani memanfaatkan tanah pertanian/sawahnya untuk dijadikan batu bata. Karena kebutuhan pembangunan di pusat kota Makassar meningkat, maka kebanyakan memesan batu bata ke kabupaten takalar. Meningkatnya kebutuhan akan permintaan batu 
bata maka petani lain di desa parambambe ikut menjadi pengrajin batu bata memberikan nilai ekonomi yang baik, sehingga disetiap desa dikabupaten takalar mulai mengembangkan usaha ini.

Eksploitasi lahan secara besar-besaran dengan mementingkan upah sesaat, karena pengetahuan masyarakat pada kecamatan Galesong selatan khususnya desa Parambambe dengan kepadatan penduduk 2,965 jiwa (BPS Takalar, 2007) dan jika dilihat dari tingkat pendidikan yang masih dibawah rata-rata dan kebanyakan dari mereka adalah petani mengakibatkan lahan bekas galian pembuatan batu bata setelah tanahnya di ambil, mereka tidak tahu bagaimana memanfaatkan dan mengolah lahan tersebut agar dapat meningkatkan penghasilan mereka. Dan jika ditinjau dari segi lingkungan akan memberikan dampak negatif pada ekosistem sekitar.

Untuk mengatasi permasalahan diatas yang dialami oleh mitra maka pelaksana kegiatan Ipteks bersama-sama dengan mitra akan melakukan hal-hal sebagai berikut: a) Bersama mitra mengembangkan usaha perikanan air tawar; b) Mengembangkan sistem pemeliharaan ikan dengan sistem kolam semen dan sistem kolam karpet yang akan disesuaikan dengan kebutuhan dan kondisi lahan mitra; c) Pelaksana kegiatan sesuai dengan bidang ilmu akan memberikan pelatihan, pengarahan, dan manajemen pemasaran mengenai pembudidayaan ikan air tawar, dan mitra menerima program kegiatan Ipteks; d) Bersama mitra mencegah kerusakan lingkungan lahan sekitar akibat penggalian untuk dijadikan batu bata.

\section{METODE PELAKSANAAN}

Metode pelaksanaan kegiatan Program Kemitraan Masyarakat (PKM), dan solusi yang ditawarkan adalah sebagai berikut:

1. Melakukan pelatihan kepada masyarakat Kecamatan Galesong Selatan dalam mengembangkan usaha perikanan air tawar, metode yang digunakan adalah ceramah, diskusi dan, tanya jawab.
2. Membantu masyarakat Kecamatan Galesong Selatan mengembangkan sistem pemeliharaan ikan dengan sistem kolam semen dan sistem kolam karpet yang akan disesuaikan dengan kebutuhan dan kondisi lahan, metode yang digunakan adalah praktek langsung dan pengamatan.

3. Melatih masyarakat Kecamatan Galesong Selatan memberikan pelatihan, pengarahan, dan manajemen pemasaran mengenai pembudidayaan ikan air tawar, dan mitra menerima program kegiatan Ipteks. Metode yang digunakan adalah demonstrasi.

4. Memberikan penyuluhan kepada masyarakat Kecamatan Galesong Selatan mencegah kerusakan lingkungan lahan sekitar akibat penggalian untuk dijadikan batu bata. Metode yang digunakan adalah ceramah, diskusi dan, tanya jawab.

\section{HASIL DAN PEMBAHASAN}

\section{A. Realisasi Penyelesaian Masalah}

Terdapat dua pendekatan yang digunakan dalam pelaksanana pengabdian tersebut, yaitu pendekatan pelatihan dan pendampingan. Pada kegiatan pertama, yaitu pelatihan, masyarakat mendapatkan pelatihan mengenai cara-cara dalam memanfaatkan lahan bekas galian batu bata menjadi kolam ikan lele. Pada pelaksanaan pelatihan, nampak sekali bahwa para peserta pelatihan yang terdiri dari 10 orang warga masyarakat sangat antusias dalam mengikuti pelatihan tersebut. Para peserta pelatihan sangat aktif mengajukan berbagai pertanyaan yang berkaitan dengan bagaimana cara melakukan pemanfaatan lahan bekas galian menjadi kolam ikan lele, dan mengutarakan permasalahanpermasalahan yang mereka miliki. Terjadi dialog dua arah yang aktif dalam pelatihan ini. Warga desa Parambambe sangat antusias dalam mengikuti pelatihan ini karena mereka menganggap bahwa pelatihan ini sangat penting dan dapat memberikan keterampilan terbaru bagi mereka dalam melakukan pemanfaatan lahan bekas galian menjadi kolam ikan lele walaupun hanya dasar-dasarnya 
saja dan para peserta pelatihan dapat menyegarkan kembali pengetahuan mereka tentang hal-hal yang berkaitan dengan pemanfaatan lahan bekas galian menjadi kolam ikan lele. Pada akhir kegiatan pelatihan, para peserta pelatihan memperoleh informasi yang sangat berguna untuk menambah pengetahuan mereka tentang pembuatan kolam ikan terpal, pembuatan kolam ikan semen, dan cara budidaya ikan lele yang belum pernah diperoleh menjadi informasi baru.

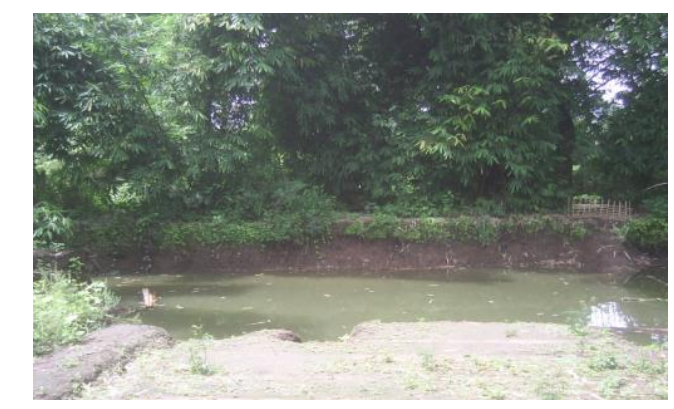

Gambar 1. Kunjungan ke lokasi mitra yakni lahan bekas galian batu bata yang tidak termanfaatkan

\section{B. Penyampaian Materi Pelatihan}

Kegiatan dilaksanakan di Kabupaten Takalar. Penyampaian materi pelatihan dilakukan dengan 3 metode yakni; metode ceramah, demontrasi dan simulasi dan penugasan. Kegiatan di ikuti oleh remaja dan kelompok masyarakat yang bermata pencaharian sebagai petani dan penjual ikan lele dengan berbagai latar belakang lingkungan sebanyak 15 orang. Alat dan bahan yang dibutuhkan dalam menunjang kegiatan pelatihan ini berupa; proyektor LCD digunakan untuk simulasi dan penyampaian materi, peralatan servis, bahan servis, alat ukur, laptop atau komputer dan CD-R.

\section{Desain Kolam Semen}

Konstruksi kolam semen adalah kolam yang dasarnya maupun sisi-sisi dindingnya dibuat dari buis beton dengan luas minimal $1 \mathrm{~m}^{2}$. Kolam semen dapat mengatasi resiko-resiko yang terjadi pada kolam gali maupun kolam terpal. Pembuatan kolam dapat dilakukan di pekarangan ataupun di halaman rumah yang sempit/luas lahan terbatas. Desain Perencanaan kolam dirancang seminimal mungkin menggunakan ruang secara horizontal, namun kolam dirancang secara vertikal sejajar sesuai dengan ketersediaan lahan di pekarangan.

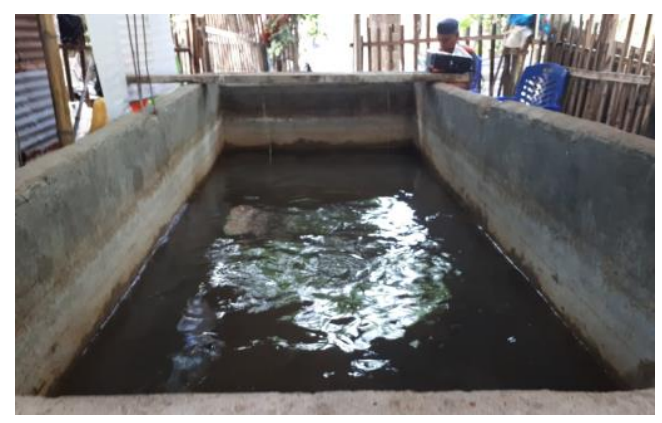

Gambar 2. Kolam Semen yang sudah jadi

\section{Desain Kolam Terpal}

Kolam terpal merupakan jenis kolam yang banyak dimanfaatkan oleh pelaku usaha budidaya lele. Kolam terpal banyak dipilih pembudidaya karena memiliki banyak keunggulan yaitu pembuatannya lebih praktis, biaya pembuatan relatif murah, dapat dibuat di lahanlahan sempit serta mudah dipindahkan dan dibongkar pasang. Kolam terpal plastik mempunyai nilai efisiensi dan efektivitas untuk budidaya lele.

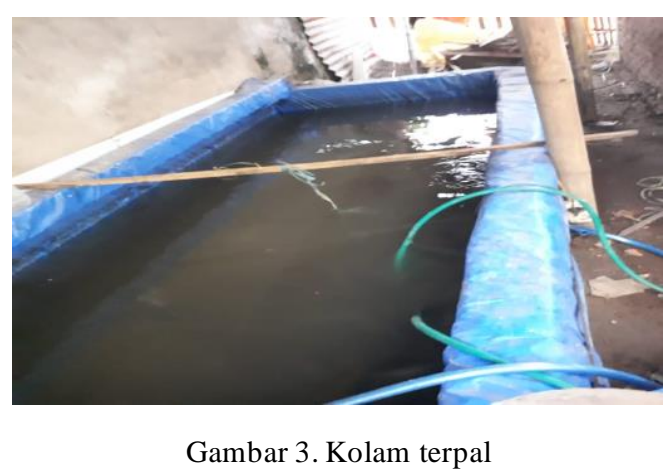

\section{E. Pemeliharaan}

Ikan lele (Clarias) adalah jenis ikan yang paling mudah ditemui. Ikan ini dapat hidup di air tawar, sedikit payau atau di dataran rendah. Di alam lele dapat kita temui di danau, waduk, rawa, sumur, parit serta sungai yang airnya tidak berarus deras. Lele lebih menyukai hidup di air yang tenang dan lingkungan yang terlindungi, teduh dan gelap. Sebagai tempat perlindungan, lele biasanya membuat lubang sebagai tempat bersembunyi dengan menggali tanah pada tepian sumur, parit atau sungai. 


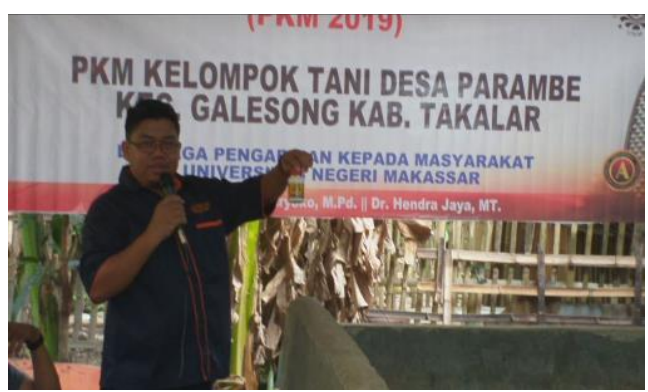

Gambar 4. Pemberian pakan (umur 1 - 2 minggu)

\section{F. Hasil yang Dicapai}

Kegiatan pengabdian ini telah dilaksanakan di di Desa Parambambe, Kecamatan Galesong Selatan, Kabupaten Takalar yang dimulai dari bulan Maret sampai bulan Agustus 2019. Program pengabdian ini bertujuan untuk mengembangkan usaha perikanan air tawar. Salah satu upaya yang sangat baik karena daerah ini juga merupakan dataran rendah, akan dilatihkan kepada masyarakat untuk memulai memelihara ikan air tawar dimulai dengan membuat kolam ikan dari lahan yang tidak termanfaatkan tersebut. Perairan tawar (fresh water) di Indonesia, saat ini masih memiliki potensi yang cukup besar untuk dimanfaatkan sebagai lahan budidaya ikan. Apabila dibandingkan dengan luas perairan yang ada, hasil budidaya ikan air tawar di Indonesia belum maksimal. Sumber daya alam ini belum termanfaatkan dengan baik (Cahyono, 2000).

Tingkat ketercapaian program pengabdian ini sangat tinggi sesuai dengan luaran yang telah direncanakan. Luaran pertama adalah penerapan teknologi tepat guna untuk pembuatan kolam ikan lele. Untuk memanfaatkan lahan yang kosong akibat bahan galian batu merah, maka dibuat kolam semen dan kolam terpal.

\section{G. Faktor Pendukung}

Proses pelatihan pemanfaatan lahan bekas galian batu merah menjadi kolam ikan lele desa Parambambe kecamatan Galesong berjalan sangat baik dan antusiasme peserta pelatihan sangat tinggi. Untuk melihat tingkat keberhasilan pelatihan didasarkan pada beberapa aspek indikator penilaian yang dilakukan yang diperlihatkan pada Gambar 5.

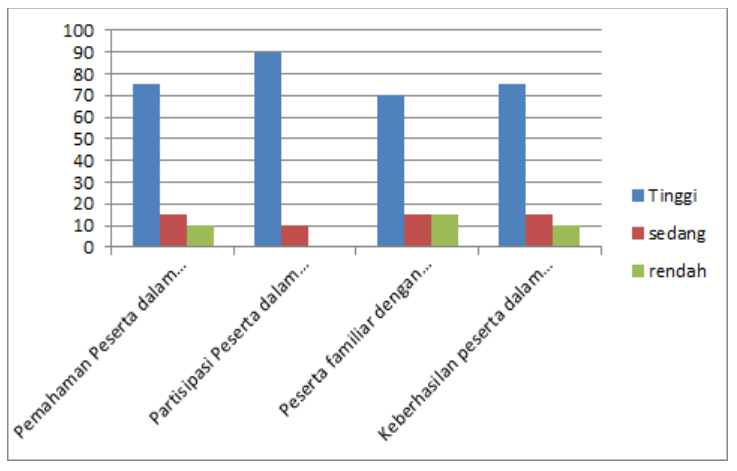

Gambar 5. Grafik penilaian keberhasilan pelatihan

Berdasarkan hasil yang telah dicapai tersebut, maka pelaksanaan pelatihan pemanfaatan lahan bekas galian menjadi kolam ikan lele di Desa Parambambe Kecamatan Galesong Kabupaten Takalar dapat berhasil karena prosentase indikator pelatihan dapat tercapai dengan skor tinggi. Sehingga pada akhir pelatihan Camat dan pemerintah daerah berkeinginan agar melaksanakan pelatihan kembali kabupaten Takalar dengan memilih daerah potensial untuk budidaya perikanan lele.

\section{H. Faktor Penghambat}

Pelaksanaan pengabdian kepada masyarakat dengan tema PKM Kelompok Tani Desa Parambambe Kabupaten Takalar telah terlaksana dengan baik. Meskipun demikian, pada pelaksanaan tersebut bukan berarti tidak menemui berbagai hambatan. Salah satu hambatan yang ditemui pada kegiatan workshop adalah kekurang percaya dirian para peserta workshop dalam mempraktekkan proses pembuatan kolam terpal dan kolam semen. Pada kegiatan ini ditargetkan bagi para peserta pelatihan untuk dapat menjelaskan dengan tuntas proses budidaya ikan lele, pembuatan kolam semen dan kolam terpal. Untuk mengatasi permasalah tersebut dilakukan pendampingan yang semaksimal mungkin.

\section{KESIMPULAN}

a. Peserta pelatihan memperoleh pengetahuan mengenai Pemanfaatan Lahan Bekas Galian Batu Bata dan Dampaknya terhadap lingkungan, pengenalan Teknik budidaya ikan lele (Pemeliharaan dari bibit hingga Layak 
Jual), pengenalan Teknik budidaya ikan lele (Manajemen Pemasaran dan Prospeknya), Pembuatan Kolam Terpal \& Kolam Semen.

b. Berdasarkan hasil yang telah dicapai tersebut, maka pelaksanaan pelatihan kepada warga (petani) Desa Parambambe Kecamatan Galesong Kabupaten Takalar dapat berhasil karena prosentase indikator pelatihan dapat tercapai dengan skor tinggi. Sehingga pada akhir pelatihan Camat dan pemerintah daerah berkeinginan agar melaksanakan pelatihan kembali kabupaten Takalar.

\section{UCAPAN TERIMA KASIH}

Ucapan terima kasih disampaikan kepada Rektor UNM atas arahan dan pembinaanya selama proses kegiatan Pengabdian Masyarakat berlangsung. Demikian pula ucapan terima kasih disampaikan kepada Ketua Lembaga Penelitian dan Pengabdian Kepada Masyarakat UNM dan Pemerintah Kabupaten Takalar Provinsi Sulawesi Selatan, yang telah memberi fasilitas, melakukan monitoring, dan mengevaluasi kegiatan PKM hingga selesai.

\section{DAFTAR PUSTAKA}

BPS Takalar. 2007. Takalar dalam Angka.

Cahyono, B. Budidaya Ikan Air Tawar. Yogyakarta: Kanisius. 